\title{
TELLING STORIES, LANDING PLANES AND GETTING THEM MOVING - A HOLISTIC APPROACH TO DEVELOPING STUDENTS' STATISTICAL LITERACY
}

\author{
JULIE SCOTT JONES \\ Department of Sociology, Manchester Metropolitan University \\ j.scott@mmu.ac.uk \\ JOHN E. GOLDRING \\ Department of Sociology, Manchester Metropolitan University \\ j.goldring@mmu.ac.uk
}

\begin{abstract}
The issue of poor statistical literacy amongst undergraduates in the United Kingdom is well documented. At university level, where poor statistics skills impact particularly on social science programmes, embedding is often used as a remedy. However, embedding represents a surface approach to the problem. It ignores the barriers to learning that students bring to class, which may not always be addressed solely through embedding, such as, mathematics anxiety. Instead, embedding can only work within a much deeper pedagogic model that places students at its heart, as active participants in learning. This paper examines the development of such a model within a large sociology programme, where there was an implementation of a range of pedagogic strategies to support the development of students' statistical literacy.
\end{abstract}

Keywords: Statistics education research; TCP model; Threshold concepts; Troublesome knowledge

\section{STATISTICAL LITERACY AMONGST UK SOCIAL SCIENCE UNDERGRADUATES}

\subsection{MIND THE GAP: CONTEXUALISING THE PROBLEM}

Statistical literacy is a somewhat generic term that covers a series of skills and activities, ranging from students' ability to produce and interpret statistical outputs, such as frequency tables, to being able to manipulate and analyse complex numerical data (MacInnes, 2009; British Academy, 2012). Within the social sciences such activities fall under the broad banner of quantitative skills and are typically encountered by undergraduates within compulsory research methods modules (MacInnes, 2009; Williams, Collett, \& Rice, 2004). The United Kingdom currently has a dearth of statistically literate graduate social scientists and a series of reports identify this as a longstanding problem (see, e.g., Parker, Dobson, Scott, Wyman, \& Sjöstedt-Landén, 2008; MacInnes, 2009; British Academy, 2012). The problem is a consequence of a range of factors, including, the poor teaching of mathematics in schools, disciplinary trends towards qualitative and/or overly theoretical approaches and demographic changes within academia in the UK, specifically an ageing population. In addition, sector-wide shifts

Statistics Education Research Journal, 16(1), 102-119, http://iase-web.org/Publications.php? $p=$ SERJ

(C) International Association for Statistical Education (IASE/ISI), May, 2017 
towards viewing the student as a consumer and thus the favouring of modules that can attain high levels of satisfaction in relation to Key Performance Indicators (KPIs) demanded by government and institution, is also a factor (Scott Jones \& Goldring, 2014).

There are two key consequences of this low take-up of quantitative courses. First, the UK has a graduate population that have low-level quantitative skills (Parker, et al., 2008; Hodgen, Pepper, Sturman, \& Ruddock, 2010) in comparison with graduates from other nations, such as the USA, China and India. Secondly, the UK is not replenishing its supply of quantitative researchers (MacInnes, 2009) despite the increasing demand for suitably skilled staff as we enter the era of Big Data and complex statistical modelling. Crucially, the inability to produce statistically literate graduates potentially hampers their career prospects (Vorderman, Porkess, Budd, Dunne, \& Rahman-Hart, 2011; Hodgen et al., 2010) and perhaps more importantly their ability to be active citizens within a mature democracy in an era of 24/7 information overload (British Academy, 2012). The latter point is true in relation to all citizens, not just graduates, and is one of the reasons why attempts to address the UK's quantitative skills problem increasingly focuses on schools and how the mathematics curriculum addresses statistical and data literacy.

\subsection{ADDRESSING THE GAP: NO MAGIC BULLET}

Attempts to address the quantitative skills gap within UK education have gained momentum over the past seven years due to effective campaigning and lobbying by learned societies, funding bodies and research councils. The initial response was twofold: first, funding to encourage greater use of the UK's large data infrastructure via initiatives such as the Economic and Social Research Council's (ESRC) Secondary Data Analysis Initiative (ESRC, 2015). Secondly, the ESRC's Curriculum Innovation and Researcher Development Initiatives (ESRC, n.d.) funded research into upskilling staff and students in quantitative skills. More recently, the need for a multi-pronged approach that addresses the entire educational lifecycle has emerged; there is not one solution as there is not one cause.

A key element of this is addressing mathematics skills in school leavers through the recent development of Core Maths as a post-16 qualification (Core Maths, 2015), which students in England should study if they do not pursue mathematics beyond age 16. ALevels are qualifications taken by students aged 16-18 in England and are the most advanced school qualifications; typically essential for entry to university. The majority of students in England do not pursue A-level mathematics. Core Maths is centred on functional mathematics skills as opposed to the more academic (and perhaps abstract) study of mathematics and there is a large focus within the qualification on the development of statistical and data literacy. This qualification is only in its second year and so we cannot yet identify whether this will significantly upskill school leavers in England as none have yet entered higher education or the workforce.

Relatedly, learned societies are still campaigning to increase the level of quantitative skills within some social science A-levels, such as sociology, which currently demands very low levels of statistical skills (Scott Jones \& Goldring, 2014) and no student manipulation or analysis of real quantitative data. The majority of students who pursue sociology (or related disciplines) at degree level have studied it at A-level (Scott Jones \& Goldring, 2014), which means that students in England entering sociology (or related disciplines) degree programmes do not identify quantitative work as a fundamental aspect of their discipline. This in itself can become a barrier to learning. Clearly, there is more to do in order to address statistical and data literacy in schools. 
The recent Q-Step centre programme (Nuffield Foundation, 2013), funded by the Economic and Social Research Council (ESRC), the Higher Education Funding Council

for England (HEFCE), and the Nuffield Foundation, exemplifies the acknowledgement of the need for an initiative that addresses the entire educational life course. Fifteen Q-Step centres of excellence in undergraduate quantitative methods pursue a range of activities that will increase the UK's throughput of statistically literate graduates and quantitative specialists. These activities include schools outreach, new degree programmes, and pedagogic innovation. This initiative is currently in its third (of ten) years so it is difficult to assess impact at this relatively early stage.

This paper explores a range of pedagogic strategies to address students' quantitative skills, deployed within a large sociology department in the UK, recently awarded Q-Step Centre funding. Additionally, one of the ESRC's Researcher Development Initiative grants, which had an initial focus on upskilling staff in quantitative skills but consequently led to pedagogic innovation, supported the development of material in this paper.

\subsection{EMBEDDING AS A PEDAGOGIC STRATEGY TO UPSKILL STUDENTS}

The initial tranche of research in the UK examining ways to upskill students in quantitative skills pursued an agenda of "embedding", see for example, Adeney and Carey (2011), Wathan, Brown, and Williamson (2011), and Falkingham and McGowan (2011). Embedding involves the incorporation of statistical material within non-research methods modules. As noted previously, undergraduate social scientists typically learn quantitative methods within large, compulsory research methods modules (MacInnes, 2009) with little room outside the module to apply or practice such skills. This common approach is a product of the crisis in UK quantitative methods outlined previously; there are few staff available to teach specialist options, even if students wished to select them. Concerns about low student satisfaction often results in the squeezing of statistical work into large compulsory modules where it often has to jostle for curriculum space and time with qualitative approaches.

Embedding seeks to achieve several key objectives: first, to offer students an opportunity to practice and apply quantitative skills in non-research methods modules, thus potentially improving such skills and making students feel more confident (Adeney \& Carey, 2011; Falkingham \& McGowan, 2011). Secondly, the inclusion of quantitative material within the wider curriculum potentially normalises quantitative methods for students (Wathan et al., 2011) allowing them to see such approaches as a key aspect of their discipline. This is important given the earlier points made about the A-Level curriculum. A survey of the literature suggests that the majority of approaches to embedding used in the UK involves identifying specific modules in the curriculum in which to embed material. Material may involve a specific lecture or seminar that examines some statistical outputs and then relates it to a topic within the module; or it may involve more elaborate embedding of material across a larger block of lectures. There may even be a choice of assessments on a module that include the examination of statistics.

There seems an over-reliance (Wathan et al., 2011) on the use of a quantitative specialist delivering embedded material within specific sessions as opposed to the upskilling of staff to deliver material within their own module; a strategy that perhaps reinforces students' perceptions that quantitative analysis is different and more specialist than other modules. Buckley, Brown, Thomson, Olsen, \& Carter (2015) provide one of the most detailed discussions of embedding as a strategy. However, most approaches to 
embedding have entailed a scattergun approach whereby quantitative specialists target non-quantitative staff willing to pursue embedding within their modules. In contrast, the ambition would be to develop a strategy that involves clear horizontal and vertical integration of embedding throughout the entire curriculum. The biggest obstacle is typically staff unwillingness to participate often due to their own low levels of quantitative skills (Falkinghan \& McGowan, 2011).

Embedding as a pedagogic strategy is useful and used by the authors of this paper. However, this paper argues that embedding is often overused in the UK as the solution to students' disengagement with quantitative methods, leading to a neglect of other significant barriers to students' learning of quantitative methods, such as, their anxiety towards numbers. Embedding may support students and staff but it does not empower them as learners unless used in conjunction with other strategies that target key barriers to learning. Thus, this paper argues that embedding is a complementary approach within a more complex and holistic pedagogic philosophy.

\section{A HOLISTIC APPROACH TO RAISING COMPETENT AND CONFIDENT STUDENTS}

\subsection{A TYPICAL APPROACH TO QUANTITATIVE METHODS?}

The Department of Sociology at Manchester Metropolitan University (henceforth MMU) is one of the largest departments of sociology in the UK, with almost 800 undergraduate students across three years of study. The profile of the students is in many ways typical in the UK; $80 \%$ are female and the majority have studied the subject at Alevel (British Sociological Association, 2013). However, in other ways, the student population is not typical; there are above-average numbers of non-traditional entry students, black-and-minority-ethnic students, mature students and students from the lowest socio-economic backgrounds. The diversity of the student body demands a complex approach to curriculum design and delivery.

Before 2012, the Department of Sociology at MMU was extremely typical in relation to how it delivered quantitative methods. Students took two compulsory research methods modules, one at year one, one at year two; both modules were a mix of qualitative and quantitative material. At year one, approximately one third of the curriculum was dedicated to quantitative methods, whereas at year two it was $50 \%$. Both modules placed the quantitative material in term two to avoid "scaring the students" as one staff member put it. Both modules used the same delivery mode of a weekly, onehour lecture and one-hour lab. There were no quantitative specialists in either teaching team; all team members admitted (via a staff survey conducted in 2011 by the authors) to not feeling confident in teaching quantitative methods and the majority of them had only undergraduate-level training. As can be seen in Table 1 below, neither module was performing well.

The curriculum at year one devoted six sessions to quantitative methods, starting with the predictably entitled lecture Lies, Damned Lies, and Statistics. The unit leader devoted more time on the critique of quantitative methods than on functional skills. Students' lab activities involved designing a questionnaire and then inputting the results of a short survey (only 20 participants required) into SPSS. There was no SPSS guidebook and little focus on core conceptual knowledge or analysis. The year-two curriculum devoted an entire term (12 weeks) to secondary data analysis, with students working up to bivariate analysis of a subset of the British Social Attitudes survey using predominantly descriptive statistics, with chi square introduced near the end of the term, without any discussion of 
the difference between descriptive and inferential statistics. There was an SPSS guidebook but there was a complete disconnect between lectures and lab sessions. Lectures on both years were traditional 'talk and chalk' sessions and there was no focus on interactivity or active learning. It was a 'one size fits all' approach to the student body, as opposed to acknowledgment of them as a diverse group of learners.

Table 1. Module data of students of the 2011-12 cohort

\begin{tabular}{cccccccc}
\hline Year & Level & Unit title & Count & Fail & Median & Satisfaction Attendance \\
\hline $2011 / 12$ & 4 Yr 1 & USR & 450 & $135(30 \%)$ & 54 & $70 \%$ & $40 \%$ \\
$2011 / 12$ & 5 Yr 2 & PSE & 215 & $37(17 \%)$ & 56 & $67 \%$ & $30 \%$ \\
\hline
\end{tabular}

Count ... Student number; Median ....median of all marks, submitted work;

Satisfaction ... Student satisfaction; Attendance ... Average weekly attendance at both classes.

USR ... Understanding Social Research; PSE ... Practice of Social Enquiry.

It is hardly surprising therefore, that neither module was well received or that a thirdyear specialist quantitative module stopped running due to lack of uptake. Unsurprisingly, few students pursued final-year dissertations that involved any form of statistical analysis, typically two per year (out of a usual dissertation cohort of $100+$ students). Clearly, change was needed and in 2011 the Programme Leader suggested that the quantitative elements of the curriculum be removed or made optional, thus condemned to die via the discourse of student choice. Fortunately, a core of research methods teachers, supported by the award of an ESRC RDI grant the same year, resisted this strongly.

The work of redesigning the quantitative modules began in 2012; the initial focus for 2012-13 was on the year-two module Becoming a Social Researcher (BSR) which had the largest quantitative component. In 2014-15 the year-one module Understanding Social Research (USR) was redesigned and by the academic year 2015-16, full vertical integration of the quantitative methods curriculum was established with a final year option - Quantitative Data Analysis (QDA) - launched to offer a specialist route. It has taken four academic years to build fully the model now in use, which the next section of this paper discusses.

\subsection{A HOLISTIC APPROACH: THE TCP MODEL}

When the authors sought to address the issues outlined in the previous section, they reviewed the existing literature in relation to teaching quantitative methods. Dissatisfied with embedding alone as a solution, a new model was developed that identified the key components of an effective quantitative skills curriculum, which drew strongly on work from outside the UK (including Sowey, 1995, 2001; Arnold, Pfannkuch, Wild, Regan, \& Budgett, 2011; Pfannkuch, Regan, Wild, \& Horton, 2010). The model took as its starting point Freire's (1996) theory of conscientisation that deconstructs the power dynamics within the learning process by placing the needs of the learners at the centre of the learning process. This approach challenges the usual model of teacher at the centre of the learning process from whom all knowledge (and power) emanates. This decentring approach has the potential to empower learners to become active consumers and producers of knowledge; it forces teachers to think through curriculum design and delivery and to cede power to learners, thus facilitating a more participatory and collaborative approach to learning (Freire, 1996). The authors went one-step further by 
identifying teaching staff (i.e., all those teaching on the quantitative modules) as learners too. The result was the Technical-Conceptual-Pedagogic-Practical (TCP) model, which incorporates four key elements necessary for an effective quantitative methods curriculum: technical, conceptual, practical and pedagogic.

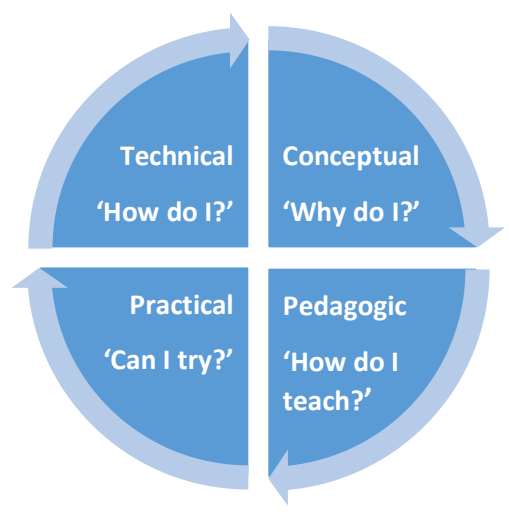

Figure 1. The TCP model

Technical - How do I? Students had to learn how to use SPSS (Statistical Package for the Social Sciences) as a data analysis tool. In the past, the year-two module had overemphasised 'clicking' over understanding, with students showing proficiency in being able to use SPSS but in an instrumental way; they knew which buttons to press but did not necessarily understand outputs or why they were running specific analyses. This over focus on the technical element of using software is commonplace (see, e.g., Sowey, 1995; Pfannkuch et al. 2010); Scott Jones and Goldring (2015) label it the "pointy clicky" approach. It often emerges due to a lack of conceptual understanding on the part of students and often staff - staff who lack confidence can often use pointy clicky as a means to appear confident and competent. Instead of committing valuable curriculum time to showing students how to use SPSS, the project team developed an SPSS guidebook that outlined how to run this software for the activities demanded by the module. The guidebook used screenshots and worked examples to show students how to run, interpret and even write-up outputs in a specific way. The aim was threefold; first, to save time in class, which could be better used focusing on the conceptual and practical issues. Secondly, it signalled to students that the technical learning of the software was not the central element of learning quantitative analysis. Lastly and more importantly, following Freire (1996), it empowered the students to become active participants in their own learning, using the guidebook at their own pace, controlling their own learning.

Conceptual - Why do I? The need for students to learn to identify and apply key statistical concepts was the second element of the TCP model. Statistical analysis modules are challenging because they entail a new language for students to learn (see Williams, Payne, Hodgkinson, \& Poade, 2008; Pfannkuch et al., 2010), often linked to mathematical ideas with which they struggle. Often students fail to see the 'bigger picture' of how concepts fit together, which is amplified by the lack of use of these concepts elsewhere in the wider curriculum. Therefore, the project team needed to consider the delivery of conceptual knowledge; they used lectures to provide the bigger picture of the course and to signal the direction of travel for the students. Lectures became interactive environments where students explored and applied key concepts 
through a variety of means, including problem-solving exercises, worksheets, quizzes, and debates.

Pedagogic - How do I teach? A number of studies have identified the shortage of suitably qualified staff to teach quantitative methods: MacInnes (2009) notes that on average (in the UK context) there may be 3-4 staff members in a department who can teach the subject but because of the ageing profile of the discipline they may be in senior positions and not involved in teaching. Williams et al. (2004) highlight that quantitative methods is often given to new staff as more established staff avoid unpopular subjects. Yet enthusiastic and sufficiently-specialist teachers are crucial if students are to become competent in quantitative analysis (MacInnes, 2009; Williams et al., 2004; Scott Jones \& Goldring, 2014). As noted earlier, the quantitative methods curriculum within the Department of Sociology at MMU lacked specialist staff and had low levels of staff confidence in teaching quantitative methods. Clearly, staff training was the first issue for the project team, therefore they developed a staff-training course (see Scott Jones \& Goldring, 2015) and all quantitative methods teachers had to participate in the course. The teaching team were a deliberate mixture of quantitative skills and abilities, the crucial element was a desire to teach the new curriculum. To facilitate staff investment, staff were given extra workload hours to participate. The training course started with a focus on upskilling the team in quantitative skills, but soon shifted to a consideration of how to teach specific topics. Central to curriculum design meetings was a consideration of how staff would teach topics within lecture and lab.

Practical - Can I try? MacInnes (2009), Williams et al. (2004) and Scott Jones and Goldring (2014) all highlight the need for students to have opportunities to practice their quantitative learning, particularly if the only opportunity they have to apply quantitative learning is within quantitative modules. Arnold et al. (2011) identify the practical application of quantitative skills as a significant means for students to concretise conceptual knowledge. Moreover, Sowey (1995) highlights, within his five-point model for teaching statistics, that "worthwhileness" is central for student engagement and one key element of this is "practical usefulness". This is two-fold in that it allows the students to apply learnt skills and knowledge but in addition, it potentially signifies to students a wider career applicability to these skills. The latter point is timely given the increasing pressure on students in the UK to consider their post-graduation trajectories at increasingly earlier points in their studies. In order to increase practice time, the teaching team increased lab time from one to two hours for both study years. Following Sowey's (1995) model that coherence and perspective should go in tandem with the practical, the team ensured that lab activities complemented lecture material. Lab activities emphasised a 'learn by doing' approach, which involved a mixture of quizzes, lab discussions, problem-solving worksheets and set lab tasks.

Barriers to learning? Once the TCP model was formalised, the authors then devoted time to a consideration of the specific barriers to learning (and teaching) quantitative methods. This 'know thine enemies' approach was influenced by the work of Meyer and Land $(2003,2005)$ and identifies the student as an individual and not part of a generic and uniform mass. As an individual, the student brings to class their educational baggage from at least thirteen years of formal schooling; this can be positive and negative, shaping how students engage with learning (Vygotsky, 1978). The project team identified three key barriers to learning quantitative methods: mathematics anxiety, troublesome knowledge and intellectual resistance. 


\section{BARRIERS TO LEARNING}

\subsection{CONQUERING MATHEMATICS ANXIETY}

Perhaps the first key barrier to learning or indeed engaging with any form of statistical work is a fear of numbers, commonly referred to as mathematics anxiety. Onwuegbuzie and Wilson (2003), clearly influenced by Vygotksy (1978) and Bronfenbrenner (1979), identify this as an anxiety amongst students when confronted with number work because of their experience of school-based mathematics. All students in England must take GCSE-level (General Certificate of Secondary Education) mathematics; these qualifications are taken at age 16 and are a gateway to further study routes, such as A-levels. The common entry requirement for undergraduate sociology, in the UK, is a grade C in GCSE mathematics. Successive reports have highlighted the failings of GCSE to equip school leavers with functional mathematics skills (see Vorderman et al., 2011; Porkess, 2013). Vorderman et al. (2011) also highlight the ongoing problem of poor quality teaching of mathematics within UK secondary schools: many students will have experienced poor teaching. To compound this problem further, the majority of students in England drop mathematics at age 16 thus they have a minimum two-year 'maths gap' before entering university. There is also an added gender dimension to this, as the majority (approximately 70\%) of sociology students (British Sociological Association, 2013) are female and have studied a range of humanities based A-levels; they tend to have high levels of literacy and lower levels of numeracy and possibly privilege the former over the latter.

Mulhern and Wylie (2005) make the point that academics presume a range of mathematics skills that students may or may not have; Williams et al. (2008) emphasise that academics rarely examine secondary-school curricula when designing quantitative modules. At least $25 \%$ of UK universities offer no formal numeracy support for students and the majority that do target students studying traditional STEM subjects (science, technology, engineering and mathematics; Croft, Lawson, Hawkes, Grove, Bowers, \& Petrie, 2014). In a recent Higher Education Academy (HEA) survey of sociology staff who teach quantitative methods (Scott Jones \& Goldring, 2014), 94\% identified mathematics anxiety as the key barrier to learning. In the HEA's companion survey of sociology undergraduates' views on quantitative methods (Scott Jones \& Goldring, 2014) $55 \%$ of students identified mathematics anxiety as a reason for struggling with quantitative methods and $42 \%$ stated that working with numbers was 'challenging'. The MMU project team found similar results in their own annual survey of students' attitudes to statistics. This survey is conducted in week one of teaching, each new academic year, with students on the module where they first encounter quantitative methods.

The MMU Sociology students clearly identify similar attitudes as their colleagues in other institutions. To address mathematics anxiety the project team, following Mulhern and Wylie (2005), developed a bespoke numeracy diagnostic, which students would do during one of their early lab sessions (typically in week 2 of the year-one module). The original version (which ran in 2013-14) had ten questions and directly mapped onto England's year 6 (last year of primary school) Scholastic Aptitude Test (SAT) level; this test was then scrapped to create a 24-question test (launched 2014-15) that was slightly more demanding and mapped on to GCSE-level. The test is on the module's virtual learning environment (VLE) and students have one hour to complete it. 
Table 2. Student attitudes to statistics and numbers - numbers (percentages)

\begin{tabular}{|c|c|c|c|c|}
\hline Question & $\begin{array}{c}\text { Year } \\
\mathrm{N}= \\
\text { Of total cohort }\end{array}$ & $\begin{array}{c}2013-14 \\
145 \\
82 \% \\
\end{array}$ & $\begin{array}{c}2014-15 \\
128 \\
74 \% \\
\end{array}$ & $\begin{array}{c}2015-16 \\
279 \\
80 \% \\
\end{array}$ \\
\hline I enjoyed maths at school. & 'Disagree' & $71(49 \%)$ & $68(53 \%)$ & $133(48 \%)$ \\
\hline I was scared of maths at school. & 'Disagree' & $104(72 \%)$ & $76(59 \%)$ & $195(70 \%)$ \\
\hline Statistics scare me. & 'Disagree' & $82(57 \%)$ & $55(43 \%)$ & $142(51 \%)$ \\
\hline $\begin{array}{l}\text { I did not expect to have to do much studying } \\
\text { that involves numbers during my course. }\end{array}$ & 'Agree' & $92(63 \%)$ & $79(62 \%)$ & $122(44 \%)$ \\
\hline $\begin{array}{l}\text { I think students on my course should not have } \\
\text { to study topics that involve looking at statistics. }\end{array}$ & 'Disagree' & $106(73 \%)$ & $85(66 \%)$ & $211(76 \%)$ \\
\hline I'd rather write an essay than analyse numbers. & 'Agree' & $93(64 \%)$ & $91(71 \%)$ & $158(57 \%)$ \\
\hline $\begin{array}{l}\text { The idea of learning how to do statistics makes } \\
\text { me feel nervous. }\end{array}$ & 'Disagree' & $71(49 \%)$ & $56(44 \%)$ & $140(50 \%)$ \\
\hline $\begin{array}{l}\text { I feel confident using statistics to illustrate } \\
\text { essays. }\end{array}$ & 'Agree' & $56(39 \%)$ & $50(39 \%)$ & $100(36 \%)$ \\
\hline
\end{tabular}

Table 3. Numeracy diagnostic test results - numbers (percentages)

\begin{tabular}{|c|c|c|c|c|c|c|c|c|c|}
\hline \multirow[b]{2}{*}{ Cohort } & \multicolumn{2}{|c|}{ Number Highest } & \multicolumn{3}{|c|}{ Mark } & \multicolumn{4}{|c|}{ Number (rate) who achieved } \\
\hline & $\begin{array}{l}\text { who } \\
\text { took test }\end{array}$ & $\begin{array}{c}\text { score } \\
\text { possible }\end{array}$ & Median & Mean & Range & $\begin{array}{l}<40 \% \\
\text { failed }\end{array}$ & $40 \%+$ & $\begin{array}{c}50 \%+ \\
\text { passed the tes }\end{array}$ & $70 \%+$ \\
\hline $2013 / 14^{a}$ & 167 & 10 & 8.51 & 7.57 & $1-10$ & $11(7 \%)$ & $156(93 \%$ & o) $146(87 \%)$ & $103(62 \%)$ \\
\hline $2014 / 15^{b}$ & 239 & 24 & 13.5 & 12.7 & $3-24$ & $78(33 \%)$ & $161(67 \%$ & o) $136(57 \%)$ & $62(26 \%)$ \\
\hline $2015 / 16^{b}$ & 278 & 24 & 11.5 & 10.9 & $0-23$ & $100(36 \%)$ & $178(64 \%$ & o) $112(40 \%)$ & $39(14 \%)$ \\
\hline
\end{tabular}

a. Diagnostic mapped to the UK Yr6 Numeracy test level; b. Diagnostic mapped to the UK GCSE level.

The test results demonstrate the diverse range of mathematics skills within the cohort, with over a third failing overall and only a small number achieving an A grade status. The diagnostic serves two key purposes: first, the teaching team can assess the overall mathematics skills of the cohort and through an analysis of student responses, identify any shared cohort problems. For example, it became clear to the team that the 2014-15 cohort struggled with interpreting very small numbers (such as 0.003 ) due to confusion relating to decimal points. Obviously, this poses an issue when students must interpret $p$ values when running statistical tests. The teaching team therefore created a decimal point quiz on the VLE for students to do prior to labs that focused on the interpretation of $p$ values. The quiz served to provide students with an opportunity to practice interpreting values and review their own learning. In addition, the VLE hosted materials relating to the interpretation of small numbers and decimal points. The second advantage of the numeracy diagnostic is that students receive an instant report on their test scores and this links them to institutional support with numeracy; students with low tests scores receive an email advising them to seek help from the institution-wide Numeracy Project. This 
project provides both one-to-one support to students through peer-assisted learning and bespoke sessions for entire cohorts on specific numeracy issues and becomes a key element of supporting students and without it, the utility of the numeracy diagnostic would be minimised.

Supporting students' numeracy skills is one element of combatting mathematics anxiety; another key approach that the authors took was to make students see numbers differently. This strategy, dubbed 'number desensitisation', featured in the early sessions of each quantitative module. At its heart, this approach was to make students feel differently about numbers. Given that mathematics anxiety probably starts at some point within students' early experience of mathematics at school (Vorderman et al., 2011) means that students become sensitised to numbers, provoking a real emotional response (Onwuegbuzie \& Wilson, 2003). Students crying, becoming petulant or getting angry are all common responses in early lab sessions and such responses are partly a consequence of becoming overly sensitised to numbers at school. To counter this, early sessions in lecture and lab involved a range of activities to change students' response to seeing numbers, including, getting them to identify important (enjoyable) numbers in their lives such as birthdates, lucky numbers, the number on their payslips and so forth. Relatedly, students explored in the first lecture of the year-one module, the cultural significance and historical development of numbers to demonstrate that numbers (like words) have cultural and historical meanings, for example, the role of zero within an Indian spiritual context and how zero ended up being brought westwards to Europe. Finally, students were introduced to the power of numbers in an early session entitled 'Numbers Change Lives' in which case studies were presented that explored how statistical analysis has led to significant social changes, for example, Victorian analysis of mortality and disease rates within specific localities. This lecture ran in parallel with a session in the compulsory social theory module that covered the same material but with a theoretical focus, thus allowing students a sense of the connection between quantitative data, theory and social impact.

The final strategy for combatting mathematics anxiety was to communicate a narrative throughout the curriculum that 'numbers tell stories'. This focus on the narrative was a deliberate attempt to appeal to students' pre-existing narrative and critical skills. As Pfannkuch et al. (2010) note, narrative language is the key means of communication in liberal arts courses. As noted earlier, the majority of sociology students in the UK are female and studied humanities-type subjects at school (British Sociological Association, 2013). The adoption of a narrative approach to numbers particularly appealed to female students who often struggled initially to see 'beyond the number' in comparison to their male counterparts. Each lecture focused on a specific group of core concepts but throughout was illustrated with case studies; students had to identify potential narratives emerging from the analysis of the data, drawing on their wider sociological imaginations. The contested nature of analysis and the importance of linking data to theoretical frameworks was emphasised throughout sessions; again, this attempted to appeal to the discursive and critical skills, which students identify as everyday elements of their discipline. Sowey (1995) identifies the need to incorporate opportunities for students to question, debate and critique as crucial to the development of student engagement with statistics. In lab work, students had to write short stories or narratives that they saw emerging from their analysis of data. This approach allowed students to reconnect the numbers to their wider sociological conceptual frameworks, which tend to emphasise narrative and discourse. This is important because often students struggle to identify the "bigger picture" when conducting statistical analysis (Williams et al. 2008; Cuthbert, Arunachalam, \& Licina, 2012; Arnold et al., 2011). 


\subsection{TROUBLESOME KNOWLEDGE}

Quantitative methods is an obvious example of what Meyer and Land (2003, 2005) dub "troublesome knowledge", that is material that students struggle to engage with for a range of reasons. In the case of quantitative methods some of these reasons, previously outlined in this paper, include poor quality teaching delivered by staff lacking confidence in the material and the requirement to learn a new software (SPSS) not encountered previously (Scott Jones \& Goldring, 2014; MacInnes, 2009; Williams et al. 2008). However, perhaps most important of all is the demand to learn a new conceptual language that may seem very unfamiliar to students.

Threshold concepts Central to combatting "troublesome knowledge" is an acknowledgement and an identification of "threshold concepts" (Meyer \& Land 2003, 2005). "Threshold concepts" are key concepts within a curriculum, which are gatekeepers to progress on a module; students who cannot break through to understanding a threshold concept will struggle to progress on to related concepts. Quantitative methods is full of threshold concepts due to the marginalisation of the subject within the wider discipline and most curricula (Williams et al., 2008). If one also factors in mathematics anxiety then it is possible to see how many potential barriers there are to student progression with the subject (Onwuegbuzie \& Wilson, 2003). It is crucial to consider threshold concepts within curriculum design and delivery; such concepts may change depending on cohort or even class group.

Tutor needs to teach

Students

Students

don't get $X \quad$ stop learning

Tutor

$X, Y$ and $Z$ this term

Figure 2. Threshold concepts as barriers to learning

Typically, academics approach curriculum design in a linear progressive style, which presumes that all students will progress at the same pace. In addition, there is a tendency to view a module as an empty vessel to be filled; MacInnes (2009) and Williams et al. (2008) both stress that teachers of quantitative methods tend to cram as much as possible into their modules, with scant consideration of whether students can maintain the pace required. As Figure 2 illustrates, teachers start with a to-do list of what needs to be covered and expect students to progress at the same pace throughout; however, students may become stuck at an initial concept and stop progressing. If the teacher is unaware of this or fails to address it, then the students may become disengaged altogether, hindering success on the module. To combat this, the authors took a specific approach to curriculum design.

First, they adopted the philosophy of 'less is more', with a reduction in the range of material covered. There was also a clear sense of what each module sought to achieve and how year two would build on year one. A clear sense of vertical alignment facilitates a better sense of what does and does not need to be included in each module. The subsequent development of a final-year quantitative option further allowed the team to delineate core or functional material, required within years one and two, from specialist material for those opting to specialise in year three. 
Secondly, the authors designed module curricula with space, that is, in a twelve-week block, at least two sessions were identified as flexible and could be used to review material with which students struggled. For example, the 2014-15 year-two cohort struggled with understanding distribution, standard deviation, and normality. The material was revisited and delivered in a completely different manner; the second time using the analogy of landing a plane. The lecturer designed an interactive lecture using graphics to allow the students to land a virtual plane. The runway was a visualisation of a distribution of scores, with the plane as the mean; the students then had to try to land the plane according to directions from the lecturer based on standard deviation scores. This approach appealed to the students as it was engaging and dramatically visualised for them the impact of outliers and extreme scores (they sometimes crashed!). Because it was dramatic, they were able to use it as an aide memoir when struggling with interpreting output; lab tutors could remind them to 'think about the plane landing exercise'.

The 2015-16 year-two cohort has struggled more with understanding the relevance of probability and randomness at the start of their second-year module. An additional lecture approached the topic through examples from the world of sport, asking students to bet (using fake money) on the performances of specific soccer teams and individual players; they then linked their choices back to probability.

The ethos of 'slow, slow' is embedded within the curriculum and students are encouraged to view the learning process as 'slow' rather than 'fast'; relatedly they are encouraged to learn through reflection on their mistakes. In order to identify threshold concepts within specific cohorts, concept testing is vital and so the modules' VLEs were used to deliver quizzes, self-tests, and exploratory case studies for analysis, as a means to gauge student learning. Additionally in lectures and labs, interactive software, including Kahoot quizzes and Socrative discussions, helped facilitate whole-group testing and learning. Teaching teams reflected on the results of these tests, via weekly team meetings and developed interventions or revisions when necessary.

Scaffolding learning An approach that places the student at the centre (Freire, 1996) requires that there are means within a module design to allow students to take control of their own learning. One technique utilised by the authors was "scaffolding" (Vygotsky, 1978; Wood \& Wood, 1996), whereby mechanisms are put in place for students to assess and reflect upon their own learning. Concept testing and the SPSS guidebook discussed earlier are two such examples. In addition, every lecture session began with a visualisation of the entire module, highlighting every key concept that the students would learn; this provided a roadmap of the module, allowing students to see their direction of travel and perhaps understand the bigger picture. Often students printed off this visual and placed it in their folders for reference. Following this visual, lecturers would recap the previous week's learning before moving on to the new material; lectures would end with a preview of the forthcoming material by the following week's lecturer. Again, this technique allowed a roadmap to emerge; one offshoot of this approach is that it developed a more effective teaching team as staff observed each other's teaching on a regular basis.

One popular technique introduced was the 'pink cards' (so named because they were printed on pink paper), which was a list of key lab tasks to be completed within ten lab sessions (see the Appendix for a copy of the task card for the year-one module). This was a formative assessment; each lab task linked to the end of module assessment. The pink cards were given to all students who worked through the tasks at their own pace; tutors would sign off each task once they considered the student to be competent at the task. Students and tutors agreed jointly when tasks could be signed off thus emphasising the 
collaborative nature of the learning environment. The pink cards thus allowed staff and students alike to assess learning: it provided students with a roadmap to the assessment and it allowed students to view their learning as incremental and progressive, usually leading to greater confidence in doing the summative assessment. Students became invested in the pink cards and would openly chivvy staff if they were tardy in signing-off a task; they often became competitive with classmates too, which again facilitated greater engagement with the subject.

Addressing learning styles As Vygotsky (1978) noted students are individual learners and linked to this is the acknowledgement that individuals have different learning styles, often related to personality and early experiences of education. Yet, too often university curricula teach students as a generic group. Given the challenging nature of teaching and learning quantitative methods, the authors decided that teaching materials, particularly in lectures, would address different learning styles. A number of different styles were targeted (Fleming \& Mills, 1992): practical, kinaesthetic, visual, narrative, and problem solving.

Practical learners learn by doing; thus lab work focused overwhelmingly on the active 'doing' of statistical analysis, via the weekly lab tasks. In addition, lab sessions and many lectures had an emphasis on solving 'problems' via case studies. For example, a mock scenario where students imagined a future boss asking them to analyse some workplace data on employer satisfaction. They had a list of variables and a central research question; they then had to decide which would be the most effective statistical tests to run to provide their boss with the 'answer' she sought. Another case study asked the students to review three mock studies, identify flaws in the sampling strategies utilised, and suggest ways to improve the results. The use of visualisation as an effective way to teach quantitative methods features in several studies (see, e.g., Signoretta, Chamberlain, \& Hillier, 2014). The proliferation of online statistical resources facilitates this greatly; for example, on the year-one module students use the interactive resources on the police website (UK Police, n.d.) to examine crime mapping and hotspots. In addition, the teaching team use graphics, such as flow charts, to visualise the process of statistical analysis for students, partly as a road mapping exercise but also to provide them with a set of 'how to build' instructions for analysis depending on data type.

The teaching team's 'using numbers to tell stories' strategy addresses those students who learn through narrative. Finally, kinaesthetic learning (learning through movement) has been used widely within lecture and lab. For example, to demonstrate the concept of range and distribution, including the potential impact of extreme scores, a group of male students volunteered to stand at the front of the lecture hall. The students then had to arrange themselves in a height order, aided by the rest of the class. The class had to identify the range and work out the middle score; the impact of a particularly tall student was assessed. Then the class were asked to predict how things might change if we added some female students; this was tested by female volunteers joining the height line. As well as being a fun activity (the students approached it in a lighthearted manner), it provided an example, which staff could refer to in lab to reiterate the key concepts. Staff in lecture and lab also developed the use of particular hand gestures to identify specific concepts; students were encouraged to use these gestures themselves as a way to remember the concepts. For example, to aid students' learning of the distinction between one and two tailed hypotheses, staff would outstretch their right arm and point, as if they were giving someone a direction, which indicated one-tailed; and do outstretched and open arms, which indicated two tailed. Students soon started to copy this in lab. Another example of this was in relation to the distinction between population (denoted by $\mathrm{N}$ ) and 
sample (denoted by $\mathrm{n}$ ). The year-one students initially struggled with this, so the teaching team developed the following gesture: right finger and thumb close together indicating something small ('little n'), right hand and left hand apart but parallel indicating a large space ('big N'). Again, the students started to copy this gesture. Although based on observational evidence, the teaching team noticed that female students preferred the narrative approaches whereas the males found the kinaesthetic techniques more useful; this observation would warrant further study.

\section{EVALUATING THE TCP MODEL}

\subsection{MEASURING IMPACT}

An examination of key module metrics is one means to evaluate the impact of the TCP model and the different pedagogic strategies utilised by the authors in conjunction with their teaching teams. Perhaps the most crucial is student performance in these modules. Table 4 highlights the cohort performance data for year-two students on their compulsory quantitative methods module.

Table 4. Cohort performance data, Year-two students - numbers (percentages)

\begin{tabular}{|c|c|c|c|c|c|c|c|c|c|}
\hline Year & $\begin{array}{l}\text { Unit } \\
\text { level }\end{array}$ & $\begin{array}{l}\text { Unit } \\
\text { title }\end{array}$ & $\begin{array}{l}\text { Student } \\
\text { N }\end{array}$ & $\begin{array}{l}\text { Non sub- } \\
\text { mission }\end{array}$ & Fail & Median & $\begin{array}{c}40 \%+ \\
\text { Number } \\
\text { (rate) }\end{array}$ & $\begin{array}{c}60 \%+ \\
\text { Number } \\
\text { (rate) }\end{array}$ & $\begin{array}{l}\text { Marks } \\
\text { range }\end{array}$ \\
\hline 2011-12 & 5 Yr 2 & PSE & 215 & 27 & 37 & 56.0 & $178(83 \%)$ & $52(24 \%)$ & $4-74$ \\
\hline 2012-13 & 5 Yr 2 & BSR & 257 & 7 & 9 & 63.5 & $248(96 \%)$ & $163(63 \%)$ & $22-92$ \\
\hline 2013-14 & 5 Yr 2 & BSR & 180 & 3 & 4 & 65.0 & $176(98 \%)$ & $141(78 \%)$ & $28-95$ \\
\hline 2014-15 & 5 Yr 2 & BSR & 176 & 5 & 8 & 65.0 & $168(95 \%)$ & $121(69 \%)$ & $32-92$ \\
\hline
\end{tabular}

PSE ... Practice of Social Enquiry; BSR ... Becoming a Social Researcher. Non submission ... at first attempt; Late submission ... within one week of sub date.

The performance data indicates a clear change in student performance and behaviour between the 2011-12 cohort and the subsequent post-intervention cohorts: the pass rate increases to almost $100 \%$; there is an increase in overall student grades, with the majority of students achieving high marks ( $60 \%$ plus); the median mark has increased; and the majority now submit work on time. Although the cohort size has reduced, it should be noted that the staff-student ratio (1:25) was maintained, thus the potential effect of smaller lab classes is not a factor. Although the size of the cohort changed, the composition in terms of key demographics (such as mathematics qualifications on entry, overall grade averages on entry, gender, ethnicity and socio-economic background) did not, so the change is not due, for example, to the recruitment of more numerically proficient students.

However, the core module assessment task itself did not change significantly between the three post-intervention cohorts, thus the data suggests that students have increased in their quantitative competency as measured by assessment scores.

An additional indicator of increased confidence (and engagement with quantitative analysis) is the fact that 35 students (20\% of the 2014-15 year-two cohort) opted to 
pursue quantitative analysis in their final year through enrolment on a new 'with quantitative methods' programme that entailed them conducting a quantitative dissertation and studying an advanced statistical analysis optional module. Another way to chart student engagement is through student satisfaction surveys; MMU conducts its own Internal Student Satisfaction Survey. Each term students rate their modules and provide free text comments on what works and does not work for them. The key metrics are the satisfaction scores, aggregated from a five-point Likert scale, with the neutral response removed from the published results. Obviously, the possibility to infer too much from the data is limited by varying response rates and by the bluntness of the survey tool itself, which does not provide rating of specific aspects of the module.

Table 5. Year-2 module satisfaction data-Percentages and numbers

\begin{tabular}{|c|c|c|c|c|c|}
\hline Cohort & $\begin{array}{l}\text { Module } \\
\text { title }\end{array}$ & $\begin{array}{c}\mathrm{N} \\
\text { students }\end{array}$ & $\begin{array}{c}\text { Response } \\
\text { number (rate) }\end{array}$ & $\begin{array}{l}\text { Overall I am satisfied } \\
\text { with this unit }\end{array}$ & $\begin{array}{l}\text { Overall I am dissatisfied } \\
\text { with this unit }\end{array}$ \\
\hline 2011-12 & PSE & 214 & $96(45 \%)$ & $67 \%$ & $23 \%$ \\
\hline $2012-13$ & BSR & 252 & $139(55 \%)$ & $78 \%$ & $18 \%$ \\
\hline 2013-14 & BSR & 177 & $115(65 \%)$ & $94 \%$ & $3 \%$ \\
\hline 2014-15 & BSR & 173 & $100(58 \%)$ & $90 \%$ & $8 \%$ \\
\hline
\end{tabular}

PSE ... Practice of Social Enquiry; BSR ... Becoming a Social Researcher

Despite its limitations, the data demonstrates that students show good levels of satisfaction with the teaching and content of the year-two module. The higher dissatifaction for the 2012-13 cohort may be partly attributed to the fact that the cohort encountered the quantitative curriculum in term two, following a term of qualitative methods. Therefore their quantitative methods gap between years one and two was longer than that of subsequent cohorts. Perhaps also having qualitative methods first may have reinforced typically negative student attitudes and stereotypes towards statistical analysis. The key metrics data, taking into account its inherent limitations, suggests that the TCP model has had some impact on student experience and engagement.

\subsection{FINAL COMMENTS}

The TCP model owes part of its success to departmental and latterly institutional commitment to pedagogic innovation, through resourcing and investment in infrastructure, including equipping labs for interactivity. Staff, too, need incentivisation and workload credit if lasting change is an ambition. The wider departmental culture has to value quantitative methods as an intrinsic part of the programme; this is where embedding can be a useful tool for normalising quantitative methods for both staff and students. Long-term investment and commitment is therefore required to support pedagogic innovation to ensure significant and sustainable impact on students' statistical literacy.

\section{ACKNOWLEDGEMENTS}

This work was supported by the Economic and Social Research Council under grant number ES/J011703/1. 


\section{REFERENCES}

Adeney, K. \& Carey, S. (2011). How to teach the reluctant and terrified to love statistics: The importance of context in teaching quantitative methods in the social sciences. In G. Payne \& M. Williams (Eds.), Teaching quantitative methods: Getting the basics right (pp. 85-98). London: Sage Publications.

Arnold, P., Pfannkuch, M., Wild, C. J., Regan, M., \& Budgett, S. (2011). Enhancing students' inferential reasoning: from hands-on to "movies". Journal of Statistics Education, 19(2). [Online: www.amstat.org/publications/jse/v19n2/pfannkuch.pdf]

British Academy (2012). Society counts - Quantitative studies in the social sciences and humanities. [Online: www.britac.ac.uk/publications/society-counts-quantitativestudies-social-sciences-and-humanities]

British Sociological Association (2013). Mapping sociology. Unpublished Project report. Durham: British Sociological Association.

Bronfenbrenner, U. (1979). The ecology of human development: Experiments by nature and design. Cambridge, MA: Harvard University Press.

Buckley, J., Brown, M., Thomson, S., Olsen, W., \& Carter, J. (2015). Embedding quantitative skills into the social science curriculum: case studies from Manchester. International Journal of Social Research Methodology, 18(5), 495-510.

Core Maths (2015). Core maths. [Online: www.core-maths.org/]

Croft, T., Lawson, D., Hawkes, T., Grove, M., Bowers, D., \& Petrie, M. (2014). SIGMAA network working. [Online:

www.sigma-network.ac.uk/wp-content/uploads/2014/10/sigma-A-network-working.pdf]

Cuthbert, D., Arunachalam, D., \& Licina, D. (2012). 'It feels more important than other classes I have done': An 'authentic' undergraduate research experience in sociology. Studies in Higher Education, 37(2), 129-142.

ESRC (2015). Secondary data analysis initiative. Swindon, England: Economic and Social Research Council.

[Online: www.esrc.ac.uk/research/our-research/secondary-data-analysis-initiative/]

ESRC (n.d.). Quantitative methods initiative. Swindon, England: Economic and Social Research Council. [Online: www.quantitativemethods.ac.uk/]

Falkingham, J. \& McGowan, T. (2011). Improving the teaching of quantitative methods to undergraduate social scientists: Understanding and overcoming the barriers. In G. Payne \& M. Williams (Eds.), Teaching quantitative methods: Getting the basics right (pp. 99-120). London: Sage Publications.

Fleming, N. D. \& Mills, C. E. (1992). Not another inventory, rather a catalyst for reflection. In D. H. Wulff \& J. D. Nyquist (Eds.), To Improve the Academy (Vol. 11, pp. 137-155). Professional and Organisational Development Network in Higher Education. Stillwater, OK: News Forums Press.

Freire, P. (1996). Pedagogy of the oppressed. London; Penguin.

Hodgen, J., Pepper, D., Sturman, L., \& Ruddock, G. (2010). Is the UK an outlier? An international comparison of upper secondary mathematics education. London: Nuffield Foundation. [Online:

www.nuffieldfoundation.org/sites/default/files/files/Is\%20the\%20UK\%20an\%20Outl ier_Nuffield\%20Foundation_v_FINAL.pdf]

MacInnes, J. (2009). Proposals to support and improve the teaching of quantitative research methods at undergraduate level in the UK. Swindon, England: Economic and Social Research Council. [Online: www.esrc.ac.uk/files/research/qmi/finalreport-strategic-advisor-for-quantitative-methods-proposals-to-support-and-improvethe-teaching-of-quantitative-research-methods-at-undergraduate-level-in-the-uk/] 
Meyer, J. H. F. \& Land, R. (2003). Threshold concepts and troublesome knowledge: Linkages to ways of thinking and practising within the disciplines. In C. Rust (Ed.), Improving student learning: Improving student learning theory and practice - Ten years on (pp. 431-443). Oxford: Oxford Centre for Staff and Learning Development.

Meyer, J. H. F. \& Land, R. (2005). Threshold concepts and troublesome knowledge (2): Epistemological considerations and a conceptual framework for teaching and learning. Higher Education, 49(3), 373-388.

Mulhern, G. \& Wylie, J. (2005). Mathematical prerequisites for learning statistics in psychology: assessing core skills of numeracy and mathematical reasoning among undergraduates. Psychology Learning and Teaching, 5(2), 119-132.

[Online: journals.sagepub.com/doi/pdf/10.2304/plat.2005.5.2.119]

Nuffield Foundation (2013). Q-Step. A step-change in quantitative social science skills. .

[Online: www.nuffieldfoundation.org/q-step]

Onwuegbuzie, A. J. \& Wilson, V. A. (2003). Statistics anxiety: Nature, etiology, antecedents, effects, and treatments - A comprehensive review of the literature. Teaching in Higher Education, 8(2), 195-209.

Parker, J., Dobson, A., Scott, S., Wyman, M., \& Sjöstedt-Landén, A. (2008). International benchmarking review of best practice in the provision of undergraduate teaching in quantitative methods in the social sciences.

[Online: www.esrc.ac.uk/files/research/qmi/international-benchmarking-review-ofbest-practice-in-the-provision-of-undergraduate-teaching-in-quantitative-methods-inthe-social-sciences-final-report/]

Pfannkuch, M., Regan, M., Wild, C., \& Horton, N. J. (2010). Telling data stories: Essential dialogues for comparative reasoning. Journal of Statistics Education, 18(1). [Online: www.amstat.org/publications/jse/v18n1/pfannkuch.pdf]

Porkess, R. (2013). A world full of data. Statistics opportunities across A-level subjects. London: Royal Statistical Society.

[Online: www.rss.org.uk/Images/PDF/influencing-change/A-world-full-of-data.pdf]

Scott Jones, J. \& Goldring, J. E. (2014). Skills in mathematics and statistics in sociology and tackling transition. The Higher Education Academy STEM Project Series. York, England: Higher Education Academy.

Scott Jones, J. \& Goldring, J. E. (2015). 'I'm not a quants person': key strategies in building competence and confidence in staff who teach quantitative research methods. International Journal of Social Research Methodology, 18(5), 479-494.

Signoretta, P., Chamberlain, J. M., \& Hillier, J. (2014). 'A picture is worth 10,000 words': A module to test the 'visualization hypothesis' in quantitative methods teaching. Enhancing Learning in the Social Sciences, 6(2), 90-104. [Online: www.tandfonline.com/doi/pdf/10.11120/elss.2014.00029?needAccess=true]

Sowey, E. R. (1995). Teaching statistics: making it memorable. Journal of Statistics Education, 3(2). [Online: ww2.amstat.org/publications/jse/v3n2/sowey.html]

Sowey, E. R. (2001). Striking demonstrations in teaching statistics. Journal of Statistics Education, 9(1). [Online: ww2.amstat.org/publications/jse/v9n1/sowey.html]

UK Police (n.d.). Crime and policing in England, Wales and Northern Ireland. [Online: www.police.uk/]

Vorderman, C., Porkess, R., Budd, C., Dunne, R., \& Rahman-Hart, P. (2011). A worldclass mathematics education for all our young people.

[Online: www.tsm-resources.com/pdf/VordermanMathsReport.pdf]

Vygotsky, L. S. (1978). Mind in society: The development of higher psychological processes. Cambridge, MA: Harvard University Press. 
Wathan, J., Brown, M., \& Williamson, L. (2011). Increasing secondary analysis in undergraduate dissertations: A pilot project. In G. Payne \& M. Williams (Eds.), Teaching quantitative methods: Getting the basics right (pp. 121-141). London: Sage Publications.

Williams, M., Collett, T., \& Rice, R. (2004). Baseline study of quantitative methods in British sociology. Plymouth, England: University of Plymouth.

Williams, M., Payne, G., Hodgkinson, L., \& Poade, D. (2008). Does British sociology count? Sociology students' attitudes toward quantitative methods. Sociology, 42(5), $1003-1021$.

Wood, D. \& Wood, H. (1996). Vygotsky, tutoring and learning. Oxford Review of Education, 22(1), 5-16.

JULIE SCOTT JONES

Department of Sociology, Manchester Metropolitan University Oxford Road, Manchester, M159LL

United Kingdom

APPENDIX: TASK CARD FOR THE YEAR-1 MODULE

\begin{tabular}{|c|c|c|}
\hline & 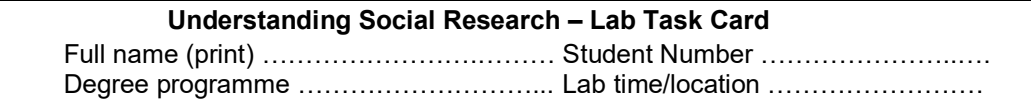 & \\
\hline $\begin{array}{l}\text { This } \\
\text { sess } \\
\text { the } 1 \\
\text { to } \mathrm{C} \\
\text { they }\end{array}$ & $\begin{array}{l}\text { ard will be given out at the start of each lab and must be returned at the end of each } \\
\text {. The card contains a series of tasks that you need to accomplish in order to complete } \\
\text { R assessment later in the term. You must demonstrate to your lab tutor that you are able } \\
\text { out each of the tasks below. Once she/he is satisfied you are competent in an area, } \\
\text { II sign your card. }\end{array}$ & $\begin{array}{l}\text { Tutor } \\
\text { signature } \\
\text { and } \\
\text { date }\end{array}$ \\
\hline 1. & Demonstrate ability to create folders/files on $\mathrm{H}$ drive. & \\
\hline 2. & Quiz for types of variables - completed online. & \\
\hline & $\begin{array}{l}\text { Produce frequency tables and an appropriate graph/chart for nominal and ordinal } \\
\text { variables. You must include a written descriptive summary for each table using the } \\
\text { instructions in the student handbook. }\end{array}$ & \\
\hline 4. & $\begin{array}{l}\text { Produce a frequency table and an appropriate graph/chart for the measures of central } \\
\text { tendency (e.g., mean, median, and mode) and dispersion (e.g., range, variance, and } \\
\text { standard deviation) for scale variables from your data set. A written descriptive } \\
\text { summary must also be included for each table. }\end{array}$ & \\
\hline 5. & Correctly identify 4 IVs and 1 DV for the data set being used. & \\
\hline 6. & Produce 4 good quality null AND operational hypotheses respectively. & \\
\hline 7. & $\begin{array}{l}\text { Prepare a literature review - using the MMU library search engine, find } 3 \text { relevant } \\
\text { journals/studies that relate to your hypotheses. These must be based on UK research. }\end{array}$ & \\
\hline 8. & $\begin{array}{l}\text { Appropriately recode the following variable types, Nominal, Ordinal and Scale (ensure } \\
\text { System Missing and All Other Values are included and that new variables are labelled). }\end{array}$ & \\
\hline 9. & $\begin{array}{l}\text { Provide a written justification of why variables were recoded. You must include both } \\
\text { theoretical/substantive AND a statistical/practical justification ( } 40 / 50 \text { words } \min / \mathrm{max}) \text {. }\end{array}$ & \\
\hline 10. & $\begin{array}{l}\text { Provide a short written rational ( } 50 \text { words) for why System Missing and All Other Values } \\
\text { can be useful when recoding. }\end{array}$ & \\
\hline 11. & Produce 2 cross tab tables and bar charts using 4 different IVs and $1 \mathrm{DV}$. & \\
\hline 12. & $\begin{array}{l}\text { Correctly produce and interpret Chi-Square and Cramer's V tables using SPSS for each } \\
\text { IV. You must include a written summary for the Chi-Square Sig. level and Cramer's V } \\
\text { (min/max } 40 / 50 \text { words). }\end{array}$ & \\
\hline 13. & Write 100 words explaining the difference between descriptive and inferential statistics. & \\
\hline & $\begin{array}{l}\text { Write a } 100 \text { words summary that explains why observed and expected counts are } \\
\text { important when calculating Chi Square. }\end{array}$ & \\
\hline 15. & Correctly interpret the observed and expected counts (min/max 40/50 words). & \\
\hline
\end{tabular}

